\title{
The influence of the level of physical activity and human development in the quality of life in survivors of stroke
}

\author{
Felipe J Aidar ${ }^{1 *}$, Ricardo J de Oliveira ${ }^{2}$, António J Silva ${ }^{1}$, Dihogo G de Matos ${ }^{1}$, André L Carneiro ${ }^{1}$, Nuno Garrido ${ }^{1}$,
} Robert $C$ Hickner $^{3}$ and Victor M Reis ${ }^{1}$

\begin{abstract}
Background: The association between physical activity and quality of life in stroke survivors has not been analyzed within a framework related to the human development index. This study aimed to identify differences in physical activity level and in the quality of life of stroke survivors in two cities differing in economic aspects of the human development index.
\end{abstract}

Methods: Two groups of subjects who had suffered a stroke at least a year prior to testing and showed hemiplegia or hemiparesis were studied: a group from Belo Horizonte (BH) with 48 people (51.5 \pm 8.7 years) and one from Montes Claros (MC) with 29 subjects (55.4 \pm 8.1 years). Subsequently, regardless of location, the groups were divided into Active and Insufficiently Active so their difference in terms of quality of life could be analyzed.

Results: There were no significant differences between BH and MCG when it came to four dimensions of physical health that were evaluated (physical functioning, physical aspect, pain and health status) or in the following four dimensions of mental health status (vitality, social aspect, emotional aspect and mental health). However, significantly higher mean values were found in Active when compared with Insufficiently Active individuals in various measures of physical health (physical functioning $56.2 \pm 4.4$ vs. $47.4 \pm 6.9$; physical aspect $66.5 \pm 6.5$ vs. $59.1 \pm 6.7$; pain $55.9 \pm 6.2$ vs. $47.7 \pm 6.0$; health status $67.2 \pm 4.2$ vs. $56.6 \pm 7.8$ ) (arbitrary units), and mental health (vitality $60.9 \pm 6.8$ vs. $54.1 \pm 7.2$; social aspect $60.4 \pm 7.1$ vs. $54.2 \pm 7.4$; emotional aspect $64.0 \pm 5.5$ vs. $58.1 \pm 6.9$; mental health status $66.2 \pm 5.5$ vs. $58.4 \pm 7.5$ ) (arbitrary units).

Conclusions: Despite the difference between the cities concerning HDI values, no significant differences in quality of life were found between BH and MCG. However, the Active group showed significantly better results, confirming the importance of active lifestyle to enhance quality of life in stroke survivors.

Keywords: Cerebrovascular Accident, Physical Activity, Stroke, Quality of Life

\section{Background}

Indicators related to health have assumed a prominent position in the measurement of human development. The incidence of disease in many countries has significantly increased in recent years [1-4]. Stroke currently occupies the third position with regard to mortality, being also the leading cause of disability in Western countries and ranking first in terms of loss of quality

\footnotetext{
* Correspondence: faidar@r7.com

'Department of Sports Science, Exercise and Health of the Trás-os-Montes e Alto Douro University, Vila Real, Portugal

Full list of author information is available at the end of the article
}

adjusted life years [1-3]. Moreover, problems related to hemiplegia, hemiparesis and aphasia occur frequently in stroke victims, and cause direct and indirect financial impacts on the public health system [4,5]. In Brazil, the disease accounts for one third of the deaths from circulatory diseases per year, and has a prominent place next to cardiovascular diseases [6].

There is epidemiological evidence that physical activity may lower mortality due to cardiovascular events, which could be explained by a lower blood pressure, an increased HDL-C and a lower incidence of diabetes in physical active people [7]. Additionally, studies have 
shown that physical activity attenuates the re-incidence of strokes and improves the quality of life (QOL) poststroke $[8,9]$.

Despite the proven positive impact of physical activity on QOL, analysis of this relationship within a framework related to the Human Development Index (HDI) is absent in the literature. There has always been a worldwide concern to measure the levels of human development. Thus, in early 1990, the HDI was created by the United Nations (UN). The HDI is a multifaceted index of human development that is based on economic indicators as well as indicators related to education and longevity. The HDI is the best known human development index [1].

Thus, this study aimed to identify differences in physical activity level and in the quality of life of stroke survivors in two cities differing in human development index ranking in Brazil.

\section{Methods}

\section{Sample}

The study included, initially, 77 people: 48 from the Metropolitan Region of Belo Horizonte (BH: Brazil HDI ranking of 80), Minas Gerais, Brazil (BHG) and 29 from Montes Claros (MC: Brazil HDI ranking of 968), Minas Gerais, Brazil (MCG) (Table 1). Later the subjects were divided into two groups (Active, and Insufficiently Active) based on the amount of physical activity performed (Table 2), regardless of the place of residence. The groups were composed of people who voluntarily sought a physical activity program offered by the Firefighters of Minas Gerais. The program assists people with special needs and organizes physical activities.

The eligibility criteria consisted of the individual having suffered a stroke at least one year prior to the study and showing sequelae, hemiplegia or hemiparesis.

The individuals were classified according to the Rankin Scale $[10,11]$, and in the BHG $33.1 \%$ had mild disability, $44.2 \%$ showed moderate disability and $22.7 \%$ higher disability. In the MCG $26.4 \%$ had mild disability,

Table 1 Age of participants in groups sorted by HDI of the cities

\begin{tabular}{cc}
\hline Belo Horizonte Group & Ocurrence/Means \pm SD \\
\hline Age (yr) & $51.5 \pm 8.7$ \\
Age-male (yr) & $50.7 \pm 7.8$ \\
Age-female (yr) & $52.3 \pm 6.8$ \\
Gender (Men/Women) (\%) & $18(37.5) / 30(62.5)$ \\
\hline Montes Claros Group & Ocurrence/Means \pm SD \\
\hline Age (yr) & $55.4 \pm 8.1$ \\
Age-male (yr) & $53.2 \pm 9.6$ \\
Age-female (yr) & $57.6 \pm 7.7$ \\
Gender (Men/Women) (\%) & $11(37.9) / 18(82.1)$ \\
\hline
\end{tabular}

Table 2 Age of participants in groups sorted by level of physical activity

\begin{tabular}{cc}
\hline Active & Ocurrence/Means \pm SD \\
\hline Age (yr) & $56.1 \pm 6.1$ \\
Age-male (yr) & $54.8 \pm 8.3$ \\
Age-female (yr) & $57.4 \pm 5.7$ \\
Gender (Men/women) (\%) & $6(28.6) / 15(71.4)$ \\
\hline Insufficiently Active & Ocurrence/Means \pm SD \\
\hline Age (yr) & $50.8 \pm 8.1$ \\
Age-male (yr) & $50.1 \pm 6.8$ \\
Age-female (yr) & $51.5 \pm 5.9$ \\
Gender (Men/women) (\%) & $20(35.7) / 36(64.3)$ \\
\hline
\end{tabular}

$48.5 \%$ showed moderate disability and $22.1 \%$ higher disability. In a second classification using the same scale, for the Active group, 29.7\% individuals had mild disability, $50.8 \%$ showed moderate disability and $19.5 \%$ higher disability. For the Insufficiently Active group 24.4\% had mild disability, $47.8 \%$ moderate disability and $27.8 \%$ higher disability.

All volunteers were informed about the study and signed a consent document in accordance with the Declaration of Helsinki (1964, revised in 1975, 1983, 1989, 1996 and 2000). The procedures were approved by the institution ethics committee.

\section{Procedures}

Data collection was performed at the time of registration for the program, and all interviews were conducted by a single experienced social services technician. The interviews evaluated the HDI, the QOL SF36 and the IPAQ, as described below.

\section{Instruments}

\section{Human Development Index-HDI}

The HDI seeks to demonstrate the success achieved in three basic human needs: access to knowledge (education), the right to a long and healthy life (longevity) and the right to a decent standard of living (income).

Regarding education (HDI-E), the indicators are the literacy rate of the population over 15 years and the proportion of people with access to primary, secondary and higher education. When it comes to longevity (HDI-L), the indicator is represented by life expectancy, whereas the indicator for income (HDI-I) is represented by the GDP per capita, which synthesizes the population's capacity to purchase goods and services, thus tending to represent the access to other dimensions not covered by the HDI.

The process of HDI determination consists of choosing upper and lower parameters for each indicator and the normalization is given by an equation that measures the distance between the observed value for the indicator and the minimum value as a proportion of the 
distance between the maximum and minimum value where $\mathrm{I}=$ (observed value-minimum value) $/$ (maximum value-minimum value). Thus, the closer the observed value is to the minimum value, the smaller is the numerator and therefore the worse the situation of development. Conversely, the closer the observed value is to the maximum value, the better the situation in terms of development.

The maximum and minimum values are defined through the observation of the world tendencies in terms of indicators for the long term, allowing periodic comparisons of the indexes obtained.

It is noteworthy that there are 27 states in Brazil, and that the HDI Table is based on the territorial division in 2000, year of completion of the last census, with 5,507 cities. The periods of interest for this study, on the other hand, correspond to the years until 2010, when the number of municipalities in the National Territory was already 5,564. Therefore, the absence of HDI was verified for 57 new municipalities. However, Minas Gerais (the state targeted by the present study) continued in the period with 853 municipalities; thereby showing no change in its geopolitical scenario (see table 3 ).

In this sense, both the HDI and its three sub-indices (HDI-E, HDI-L and HDI-I) vary (arbitrary units) between 0 and 1, being classified as 0 to 0.5 low human development, from 0.5 to 0.8 medium human development and 0.8 to 1 , high human development [12].

\section{Generic Questionnaire for the Assessment of Quality of Life} SF 36, Health Research

The "Generic Questionnaire for the Assessment of Quality of Life"-SF 36 "Health Research", previously validated [13-16], consists of 36 questions, ten of which related to functional capacity, four to physical aspects, two related to pain, five to health status, four to vitality, two associated with social aspects, three with emotional aspects, five with mental health, and one related to current health condition and one year after stroke [17].

The questionnaire is based on a review of existing instruments, taking into account functional changes and limitations, as well as social aspects [14]. The scores

\section{Table $3 \mathrm{HDI}$ and development indicators in the cities of} reference

\begin{tabular}{lccccccc}
\hline City & LEB & PCI & HDIM-L & HDI-E & HDI-I & HDI-M & NR \\
\hline Belo Horizonte & 70.520 & 557.435 & 0.759 & 0.929 & 0.828 & 0.839 & 80 \\
Montes Claros & 72.247 & 245.425 & 0.787 & 0.872 & 0.691 & 0.784 & 968
\end{tabular}

Source: Minas Gerais. João Pinheiro Foundation. United Nations (UN) [19]* Abbreviations:

HDIM-L: Municipal Human Development Index-Longevity; LEB: Life Expectancy at Birth; PCl: Per Capita Income; HDI-E: Education Index; HDI-I: Gross Domestic Income; HDI-M: Municipal Human Development Index; NR: National Ranking *This publication contained only descriptive data of HDI. range from zero to 100 (arbitrary units), with higher scores indicating better quality of life.

\section{"International Physical Activity Questionnaire"-IPAQ}

In order to verify the level of physical activities performed, the International Physical Activity Questionnaire-IPAQ was used in its short version, containing objective questions regarding the frequency and duration of the physical activities. Individuals were classified as very active, active, irregularly active and sedentary [18].

\section{IPAQ Classification}

The IPAQ contained questions about activities performed during the week prior to the questionnaire. The subjects' data were tabulated, evaluated and ranked according to the IPAQ, which divides and conceptualizes categories as follows:

- Sedentary: Not performing any physical activity for at least 10 continuous minutes during the week;

- Insufficiently active: individuals who practice physical activities for at least 10 continuous minutes per week, but insufficiently to be classified as active. For the classification of the individuals under this category, the length and frequency of the different types of activities (hiking + moderate + vigorous) were taken into account. This category is divided into two groups:

- Insufficiently Active A: Performing 10 minutes of continuous physical activity, following at least one of the above criteria: frequency 5 days/week or duration-150 minutes/week;

- Insufficiently Active B: Not meeting any of the criteria adopted for Insufficiently Active A;

- Active: Meets the following recommendations: a) vigorous physical activity- $>3$ days/week and $>20$ minutes/session; b) moderate or walking-> 5 days/week and $>30$ minutes/session; c) any activity added $>5$ days/ week and > $150 \mathrm{~min} /$ week;

- Very Active: Meets the following recommendations: a) vigorous- $>5$ days/week and $>30 \mathrm{~min} / \mathrm{session}$; b) vigorous $>3$ days $/$ week and $>20$ minutes/session $+\bmod -$ erate or walking 3-5 days/week and > 30 minutes/ session.

For the study, very active and active individuals were classified as Active, whereas insufficiently active and sedentary subjects were placed in the Insufficiently Active group.

\section{Statistics}

Statistical analysis was done with the groups (BHG and MCG) and the homogeneity of the sample was verified through the Shapiro Wilk test. Given the nonnormality of the sample, the Mann-Whitney test was used for checking the difference in quality of life in different cities, as well as for checking the difference in quality of life between active and insufficiently active groups. 
We adopted a $\mathrm{p}<0.05$, and the data analysis was carried out using SPSS for Windows version 15.0.

\section{Results}

The values for HDI are described in Table 3. It is noteworthy that both Belo Horizonte and Montes Claros are in the state of Minas Gerais, which has the second best performance in the country in economic terms. However, Montes Claros has only a moderate HDI-I economic indicator (0.691), a per capita income of 245,425, and a national HDI ranking of 968; whereas Belo Horizonte has a high HDI-I economic indicator (0.828), a per capita income of 557,435 , and a national HDI ranking of 80.

Patients coming from the cities of Belo Horizonte and Montes Claros were evaluated with respect to quality of life (Table 4).

There were no statistically significant differences between the quality of life in $\mathrm{BH}$ and $\mathrm{MC}$, which are cities with different HDI.

Subsequently, the level of quality of life in all participants was evaluated in relation to the amount of physical activity performed, according to the SF 36 questionnaire, regardless of location (Table 5).

\section{Discussion}

This study aimed to identify differences in physical activity level and in the quality of life of stroke survivors in two cities differing in economic aspects of the human development index. The main findings of the present study were that factors such as location and socioeconomic issues cannot be considered, de per si, indicators of quality of life, and that physical activity plays an important role in improving quality of life, regardless of the HDI-I economic indicator or HDI national ranking status of the city of residence.

When evaluating the indicators of HDI in the two cities, significant differences were found with regard to

Table 4 Measures of physical and mental health according to the SF 36 Questionnaire in groups

\begin{tabular}{llll}
\hline & BH & MCG & P \\
\hline Physical Health & & & \\
\hline Functional capacity & $49.1 \pm 6.0$ & $47.5 \pm 7.9$ & 0,706 \\
Physical Aspects & $61.3 \pm 6.7$ & $59.4 \pm 7.7$ & 0,804 \\
Pain & $48.2 \pm 6.2$ & $50.1 \pm 6.0$ & 0,077 \\
General Health Status & $58.8 \pm 7.9$ & $59.3 \pm 6.8$ & 0,913 \\
\hline Mental Health & & & \\
Vitality & $56.5 \pm 7.6$ & $55.2 \pm 8.2$ & 0,638 \\
Social Aspects & $55.2 \pm 6.6$ & $54.5 \pm 8.4$ & 0,103 \\
Emotional Aspects & $58.4 \pm 5.4$ & $59.3 \pm 7.9$ & 0,079 \\
Mental Health & $61.2 \pm 4.5$ & $59.1 \pm 8.5$ & 0,051 \\
\hline
\end{tabular}

${ }^{*} p<0,05$ (Mann-Whitney). Data are presented as mean \pm SD.
Table 5 Measures of physical and mental health in the Active and the Insufficiently Active Group

\begin{tabular}{llll}
\hline & Active & Insufficiently Active & P \\
\hline Physical Health & & & \\
\hline Functional Capacity & $56.2 \pm 4.4^{*}$ & $47.4 \pm 6.9$ & 0,036 \\
Physical Aspects & $66.5 \pm 6.5^{*}$ & $59.1 \pm 6.7$ & 0,042 \\
Pain & $55.9 \pm 6.2^{*}$ & $47.7 \pm 6.0$ & 0,035 \\
General Health Status & $67.2 \pm 4.2^{*}$ & $56.6 \pm 7.8$ & 0,003 \\
\hline Mental Health & & & \\
\hline Vitality & $60.9 \pm 6.8^{*}$ & $54.1 \pm 7.2$ & 0,038 \\
Social Aspects & $60.4 \pm 7.1^{*}$ & $54.2 \pm 7.4$ & 0,036 \\
Emotional Aspects & $64.0 \pm 5.5^{*}$ & $58.1 \pm 6.9$ & 0,022 \\
Mental Health & $66.2 \pm 5.5^{*}$ & $58.4 \pm 7.5$ & 0,012 \\
\hline
\end{tabular}

${ }^{*} \mathrm{p}<0,05$ (Mann-Whitney). Data are presented as mean \pm SD

per capita income (245.425 R\$ in $\mathrm{MC}$ and $557.435 \mathrm{R} \$$ in $\mathrm{BH}$ ), HDI-I, which represents the gross domestic product (0.691 in $\mathrm{MC}$ and 0.828 in $\mathrm{BH}$ ) and the position of the municipalities in the Brazilian HDI ranking $\left(968^{\text {th }}\right.$ place for MC and $80^{\text {th }}$ place for $\mathrm{BH}$ ). However, other indicators showed no major differences, such as the education-related HDI-E, which was 0.929 in $\mathrm{BH}$ and 0.872 in MC. It is noteworthy that Montes Claros, although economically poorer, has a higher life expectancy at birth (LEB) than does Belo Horizonte (72.242 yrs in $\mathrm{MC}$ and 70.520 yrs in $\mathrm{BH})$ [12]. Contrary to our findings that the economic indicators of HDI were not decisive determinants of quality of life in survivors of stroke, another study found that socioeconomic conditions and difficulties in accessing health services tend to expose people to an increased risk of death $[20,21]$.

One possible explanation for stroke survivorship and quality of life, regardless of economic indicators in HDI, can be attributed to the fact that there is now a universalized health system in Brazil. The Brazilian health care system now offers more standard treatments, more accurate diagnoses, and acts within a time considered optimal, i.e. within three hours after the stroke and with the most appropriate procedure [22-29]. In recent years there has been a downward trend in cerebrovascular problems, which allowed Brazilian indices to be close to those seen in countries like the U.S. and Canada. This is a reflection of improvements in public health policies pursued in recent years [28].

Diagnosis and treatment carried out in the early stages of stroke tend to decrease the length of stay in hospital, improve patient prospects and decrease chances of permanent sequelae. These findings from our previous study [28] leads us to believe that economic standing seems not to be a determining factor in quality of life. This explains the absence of significant differences in quality of life in patients affected by stroke in Belo Horizonte and Montes Claros, who were subjected to similar 
treatment despite the aforementioned economic differences (HDI-R BH $=0.828$ and $M C=0.691$ ). On the other hand, delayed treatment may be more difficult and leave sequelae, regardless of location [30].

Comparing our results with those of other studies, research conducted in Chile with patients who had suffered a stroke more than three years before showed better results than those found in our study in terms of quality of life. In that study, 59 patients (average age of 62 and 51\% female) were evaluated. Nearly half $(n=29$ : $49.1 \%$ ) of the patients had some limitation. Thirty patients $(50.9 \%)$ presented with functional independence, despite showing minimal sequelae. The group of stroke survivors (aged 20-36 years) achieved an average of 84 points, and the older group (average age of 75 years) achieved an average quality of life score of 63 points [31].

It is believed that changes in lifestyle play a major role in the prognosis of patients who suffered stroke $[32,33]$. Likewise, a study conducted in Japan showed that physical activity tends to reduce the risk of mortality in patients who had stroke [34]. Physical activity is also believed to be beneficial in cases of ischemic stroke, reducing the area of ischemia in animals [35-37]. Although caution should be taken when extrapolating results from animal studies to humans, it appears that physical activity may lessen the severity of stroke, improving quality of life and the capacity for work and leisure, thereby reducing the chances of new strokes and the functional imitations they can bring $[34,36]$. In this sense, physical activities can be considered the best way to improve the psychosocial indicators, quality of life and stress levels in people with physical limitations, bringing about improvements in social and emotional health [9].

Additionally, physical exercises are a major method of reducing stress and improving social and emotional well-being in people with physical limitations [9]. Specifically in relation to stroke survivors, daily physical activity can improve quality of life as confirmed in a previous study of 40 stroke survivors. We assessed participation in daily physical activity post stroke in relation to quality of life and health. The results suggest that daily physical activity on an outpatient basis is associated with a better quality of life and health in stroke survivors [38]. Similar results were obtained in a study of stroke survivors subjected to water activities [8]. Quality of life was better in the physically active stroke survivors than those who were not active [8].

\section{Conclusion}

We therefore conclude that factors such as location and socioeconomic issues cannot be considered, de per si, indicators of quality of life, and that physical activity plays an important role in improving quality of life, regardless of the HDI ranking and economic status of the city of residence.

\section{Author details}

${ }^{1}$ Department of Sports Science, Exercise and Health of the Trás-os-Montes e Alto Douro University, Vila Real, Portugal. ²University of Brasília-Unb, Brasília, Distrito Federal, Brazil. ${ }^{3}$ Human Performance Laboratory, Department of Exercise and Sport Science, and Department of Physiology, East Carolina University. Greenville, NC, USA.

\section{Authors' contributions}

FJA and DGM conceived the study. NG, ALC, AJS participated in data collections of the study, VR conducted data analysis. RJO and RCH participated in interpretation of data and manuscript preparation. All of the authors reviewed the manuscript prior to submission.

\section{Competing interests}

The authors declare that they have no competing interests. Felipe José Aidar had no contracts or financial dealings with any company related to this manuscript. Ricardo Jacó de Oliveira, António José Silva, Dihogo Gama de Matos, Nuno Garrido, André Luiz Carneiro, Robert C. Hickner and Victor Machado Reis have no consultant ships, company holdings or patents. This study did not receive any financial support for research. All authors any direct or indirect conflicts of interests related to this manuscript. All authors meet the criteria for authorship stated in the Uniform Requirements for Manuscripts Submitted to Health and Quality of Life Outcomes.

Received: 9 February 2011 Accepted: 13 October 2011 Published: 13 October 2011

\section{References}

1. Torres HG, Ferreira MP, Dinni NP: Social indicators: why build new ones as the IPRS. São Paulo perspective 2003, 17:80-90

2. Frey $J$, Jahnke HK, Bulfinch EW: Differences in Stroke Between White, Hispanic, and Native American Patients The Barrow Neurological Institute Stroke Database. Stroke 1998, 29:29-33.

3. Kjeldsen SE, Erdine S, Farsang C, Sleight P, Mancia G: 1999 WHO/ISH Hypertension Guidelines subcommittee 1999 WHO/ISH Hypertension Guidelines-highlights \& ESH update. J Hypertens 2002, 20:153-5.

4. Menotti A, Jacobs DR Jr, Blackburn $H$, Kromhout D, Nissinen A, Nedeljkovic S: Twenty-five-year prediction of stroke deaths in the seven countries study: the role of blood pressure and its changes. Stroke 1996, 27:381-7.

5. Shahar E, McGovern PG, Pankow JS, Doliszny KM, Smith MA, Blackburn H: Stroke rates during the 1980s. The Minnesota Stroke Survey. Stroke 1997, 28:275-9.

6. Pittella JEH, Duarte JE: Prevalence and pattern of distribution of cerebrovascular disease in 242 elderly people, coming from a general hospital, autopsied in Belo Horizonte, Minas Gerais, during 1976 to 1997. Arq Neuropsiquiatr 2002, 60:47-55.

7. Kokkinos P: Physical activity and cardiovascular disease prevention: current recommendations. Angiology 2008, 59(Suppl 3):26S-9S.

8. Aidar FJ, Silva AJ, Reis VM, Carneiro A, Carneiro-Cotta S: Study of quality of life in ischemic stroke and its relationship with physical activity. J Neurol 2007, 45:518-522.

9. Carod-Artad FJ: Post stroke depression (I). Epidemiology, diagnostic criteria and risk factors. J Neurol 2006, 42:169-75.

10. Haan DR, Limburg M, Bossuyt $P$, Meulen JVD, A a ronson N: The clinical meaning of rankin handicap grades after stroke. Stroke 1995, 26:2027-2030.

11. Brazilian Society of Cerebrovascular Diseases (BSCD): Working Group on Cerebrovascular Pathology of ABN. Rankin scale of disability changed and modified Barthel index. Newsletter 1999, 6:7-12.

12. United Nations Program for Development (UNPD): Human Development Report 2009. Overcoming barriers: human mobility and development Coimbra: Edições Almedina SA; 2009 
13. Brazier JE, Harper R, Jones NM, O'Cathain A, Thomas KJ, Usherwood T: Validating the SF-36 health survey questionnaire: a new outcome measure for primary care. BMJ 1992, 305:160-4.

14. Ciconelli RM, Ferraz MB, Santos W, Meirão I, Quaresma MR: Translation into Portuguese and validation of the generic assessment of quality of life 36 (Brazil SF-36). Braz J Reumatol 1999, 39:143-50.

15. Lyons RA, Perry HM, Littlepage BN: Evidence for the validity of the shortform 36 questionnaire (SF-36) in the elderly population. Age Ageing 1994, 23:182-4.

16. McHorney CA, Ware JE, Rogers W, Raczek AE, Lu JF: The validity and relative precision of the MOS short- and long-form health status scales and Dartmouth COOP charts: results from the Medical Outcomes Study. Med Care 1992, 30:253-65.

17. Brown N, Melville M, Gray D, Young T, Munro J, Skene AM: Quality of life four years after acute myocardial infarction: short form 36 scores compared with a normal population. Heart 1999, 81:352-8.

18. Hallal PC, Victora CG: Reliability and validity of the International Physical Activity Questionnaire (IPAQ). Med Sci Sports Exerc 2004, 36:556-562.

19. Minas Gerais. João Pinheiro Foundation. United Nations (UN): Indices human development by municipalities [http://www.datagerais.mg.gov.br/site/ int_minas_produtos_especiais idh.php], Access em: 06 de Julho de 2011

20. Units of Stroke: Recommendations for its development Lisbon: Directorate General of Health Services Department-Planning. Lisboa; 2001.

21. Cavalini LT, de Leon AC: Morbidity and mortality in Brazilian municipalities: a multilevel study of the association between socioeconomic and healthcare indicators. Int J Epidemiol 2008, 37:775-83.

22. Kothari RU, Hacke W, Brott T, Dykstra EH, Furlan A, Koroshetz W: American Heart Association, International Liaison Committee on Resuscitation; Cardiopulmonary resuscitation and emergency cardiovascular care Stroke. Ann Emerg Med 2001, 37:137-44.

23. Solenski NJ: Transient ischemic attacks: Part I. Diagnosis and evaluation. Am Fam Physician 2004, 69:1665-74.

24. Esteve M, Serra-Prat M, Zaldivar C, Verdaguer A, Berenguer J: Impact of a clinical pathway for stroke patients. Gag Sanit 2004, 18:197-204.

25. Maestre-Moreno JF: Stroke and resources for emergency neurological care: be on time, why? J Neurol 2006, 42:65-67.

26. Morales-Ortiz A, Amorín M, Fages EM, Moreno-Escribano A, VillaverdeGonzález R, Martínez-Navarro ML: Use of outpatient emergency system in the treatment of acute stroke in the region of Murcia. Potential impact on emergency health care of stroke. J Neurol 2006, 42:68-72.

27. Chang CF, Lin SZ, Chiang YH, Morales M, Chou J, Lein P: Intravenous administration of bone morphogenetic protein-7 after ischemia improves motor function in stroke rats. Stroke 2003, 34:558-64.

28. André C, Curioni CC, Cunha CB, Veras R: Progressive decline in stroke mortality in Brazil from 1980 to 1982, 1990 to 1992, and 2000 to 2002. Stroke 2006, 37:2784-9.

29. Pontes-Neto OM, Silva GS, Feitosa MR, de Figueiredo NL, Fiorot JA Jr, Rocha TN: Stroke awareness in Brazil: alarming results in a communitybased study. Stroke 2008, 39:292-6.

30. Mokudai T, Ayoub IA, Sakakibara Y, Lee EJ, Ogilvy CS, Maynard KI: Delayed treatment with nicotinamide (Vitamin $\mathrm{B}(3)$ ) improves neurological outcome and reduces infarct volume after transient focal cerebral ischemia in Wistar rats. Stroke 2000, 31:1679-85.

31. Díaz-Tapia V, Gana J, Sobarzo M, Jaramillo-Muñoz A, Illanes-Díez S: Studio on the quality of life in patients with ischemic stroke. J Neurol 2008, 46:652-655.

32. Unalan D, Soyuer F, Ozturk A, Mistik S: Comparison of SF-36 and WHOQOL-100 in patients with stroke. Neurol India 2008, 56:426-32.

33. Pniewski J, Szluk B: Long-term prognosis in young adults after a cerebral ischemic episode. Neurol Neurochir Pol 2000, 34:1101-10.

34. Noda H, Iso H, Toyoshima H, Date C, Yamamoto A, Kikuchi S: JACC Study Group walking and sports participation and mortality from coronary heart disease and stroke. J Am Coll Cardiol 2005, 46:1761-7.

35. Wang RY, Yu SM, Yang YR: Treadmill training effects in different age groups following middle cerebral artery occlusion in rats. Gerontology 2005, 51:161-5.

36. Herterich B, Steube D, Buhner M: Treadmill therapy in patients after ischaemic stroke. Rehabilitation 2004, 43:137-41.

37. Ding Y, Li J, Lai Q, Rafols JA, Luan X, Clark J: Motor balance and coordination training enhances functional outcome in rat with transient middle cerebral artery occlusion. Neuroscience 2004, 123:667-74.
38. Rand D, Eng JJ, Tang PF, Hung C, Jeng JS: Daily physical activity and its contribution to the health-related quality of life of ambulatory individuals with chronic stroke. Health Qual Life Outcomes 2010, 8:80.

doi:10.1186/1477-7525-9-89

Cite this article as: Aidar et al:: The influence of the level of physical activity and human development in the quality of life in survivors of stroke. Health and Quality of Life Outcomes 2011 9:89.

\section{Submit your next manuscript to BioMed Central and take full advantage of:}

- Convenient online submission

- Thorough peer review

- No space constraints or color figure charges

- Immediate publication on acceptance

- Inclusion in PubMed, CAS, Scopus and Google Scholar

- Research which is freely available for redistribution

Submit your manuscript at www.biomedcentral.com/submit
Biomed Central 